\title{
AS MARCAS DO LUSO-TROPICALISMO NAS INTERVENÇÕES DO PRESIDENTE DA REPÚBLICA PORTUGUÊS (2016-2021)
}

THE MARKS OF LUSO-TROPICALISM IN THE SPEECHES OF THE PORTUGUESE PRESIDENT (2016-2021) HUELLAS DEL LUSOTROPICALISMO EN LOS DISCURSOS DEL PRESIDENTE PORTUGUÉS (2016-2021)

\author{
Vítor de Sousa ${ }^{1}$
}

\begin{abstract}
RESUMO
O luso-tropicalismo, para além de ter servido de suporte para a política do Estado Novo português em relação aos então territórios "ultramarinos", para legitimar o colonialismo, serve hoje para dar corpo ao mito da tolerância racial dos portugueses e até a um nacionalismo integrador e universalista. Isso mesmo pode ser observado no discurso político, como no caso do atual presidente da República português, Marcelo Rebelo de Sousa, durante o seu primeiro mandato (2016-2021). As suas intervenções são mapeadas neste artigo através de uma metodologia compósita, assentando numa amostragem não probabilística (por conveniência), tendo sido também utilizada alguma análise de conteúdo. Estudar a receção do luso-tropicalismo em Portugal permite perceber como é que as ideias de Gilberto Freyre ainda ecoam no atual discurso político.
\end{abstract}

Palavras-chave: Luso-tropicalismo. Intervenções do presidente da República (2016-2021). O mito da tolerância racial dos portugueses. $\mathrm{O}$ nacionalismo português integrador e universalista. Memória.

\begin{abstract}
Luso-Tropicalism, in addition to having served as a support for the policy of the Portuguese "Estado Novo" in relation to the then "overseas" territories, to legitimize colonialism, today serves to embody the myth of racial tolerance of the Portuguese and even a nationalism integrative and universalist. This can be seen in the political discourse, as in the case of the current President of the Portuguese Republic, Marcelo Rebelo de Sousa, during his first mandate (2016-2021), mapped in this article and developed through a composite methodology, based on a non-sampling probabilistic (convenience sampling), having also used some content analysis. Studying the reception of Luso-tropicalism in Portugal allows us to understand how Gilberto Freyre's ideas still echo in the current political discourse.
\end{abstract}

Keywords: Luso-tropicalism. Interventions by the President of the Republic (2016-2021). The myth of the Portuguese racial tolerance. The integrating and universalist Portuguese nationalism. Memory.

${ }^{1}$ CECS-Communication and Society Research Center/University of Minho, Braga, Portugal/FCT-Fundação para a Ciência e a Tecnologia.

Este trabalho é apoiado por fundos nacionais através da FCT- Fundação para a Ciência e a Tecnologia. I.P., no âmbito do Financiamento Plurianual do Centro de Estudos de Comunicação e Sociedade 2020-2023 (que integra as parcerias de financiamento base, com a referência UIDB/00736/2020, e financiamento programático, com a referência UIDP/00736/2020).

Autor Correspondente: Vítor de Sousa

E-mail: vitordesousa@ics.uminho.pt

Recebido em 24 de Março de 2021 | Aceito em 07 de Julho de 2021. 


\section{RESUMÉN}

El luso-tropicalismo, además de haber servido de apoyo a la política del Nuevo Estado portugués en relación con los entonces territorios "de ultramar", para legitimar el colonialismo, sirve hoy para encarnar el mito de la tolerancia racial de los portugueses e incluso a un nacionalismo integrador y universalista. Esto se puede ver en el discurso político, como en el caso del actual presidente de la República Portuguesa, Marcelo Rebelo de Sousa, durante su primer mandato (2016-2021). Sus intervenciones se mapean en este artículo a través de una metodología compuesta, basada en un muestreo no probabilístico (por conveniencia), y también se utilizó algún análisis de contenido. Estudiar la recepción del luso-tropicalismo en Portugal permite comprender cómo las ideas de Gilberto Freyre aún resuenan en el discurso político actual.

Palabras Ilave: Estado. Sociedad. Hegemonía. Poder. Autoritarismo.

\section{Introdução}

A adoção do luso tropicalismo - ideário que o sociólogo brasileiro, Gilberto Freyre, cunhou e desenvolveu -, por parte do Estado Novo - regime fascista português que vigorou durante 48 anos, sendo derrubado com a Revolução do 25 de Abril de 1974 -, serviu para justificar a sua retórica em relação aos então territórios ultramarinos. Primeiro, enquanto colónias e, já nos anos 50 do século XX, designados de províncias. Uma dinâmica tendente a sublinhar o slogan então em vigor, "Portugal não é um país pequeno", para além de marcar posição junto da Organização das Nações Unidas, no sentido de que os movimentos independentistas que emergiam nas então "províncias ultramarinas" vissem inviabilizada a sua pretensão de autodeterminação, uma vez que pertenciam a Portugal, por via do seu "destino histórico", que remete para o século XVI e para a primeira História de Portugal conhecida, da autoria de Fernando Oliveira, que teve como seu corolário a "formulação de uma utopia (...) assente numa profissão de fé na sua perenidade para efeitos de realização de uma missão sagrada de pendor universalizante", anunciando "as grandes utopias e mitogenias sobre Portugal, que se afirmarão no século seguinte" (Franco, 2000, p. 22).

Foi assim, entre as décadas 50 e 60 do século $X X$, no quadro do luso-tropicalismo, que foi cunhada a 'portugalidade' sendo que, ainda hoje o luso-tropicalismo e as ideias de Gilberto Freyre - pelo menos aquelas de que o Estado Novo se apropriou -, ecoam no atual discurso político e cultural português. $E$, muito embora já não estejam ligadas diretamente ao colonialismo, remetem para essa época, com o por- tuguês a ser sempre encarado como aquele que promoveu uma "colonização doce", tendo uma forma particular de estar no mundo, mais benigna do que os outros povos (Castelo, 2011).

O objetivo deste artigo foi verificar se essa perceção estava correta em relação às intervenções públicas do presidente da República, Marcelo Rebelo de Sousa, durante o seu primeiro mandato (2016-2021). Uma ideia que surgiu depois de termos seguido algumas dessas intervenções, nomeadamente em datas oficiais, como o Dia de Portugal, de Camões e das Comunidades Portuguesas (10 de junho), ou as comemorações da Revolução do 25 de Abril, em que parecia haver um fio condutor em direção a essa perspetiva.

Para o efeito, através de uma metodologia compósita, numa amostragem não probabilística (por conveniência), e com alguma análise de conteúdo, foram mapeadas intervenções do presidente publicadas na página oficial da Presidência da República portuguesa (https://www.presidencia.pt/), durante o primeiro mandato de Marcelo Rebelo de Sousa, para além de ser desenvolvida uma pesquisa de notícias e de artigos de opinião nos média de e sobre o atual presidente.

\section{0 discurso político}

O discurso político é argumentativo e persuasivo. É pessoal ou assumido através da fala de um qualquer porta-voz de alguém ou de alguma instituição. A maior parte das vezes assumindo um papel normativo para o futuro que há-de vir, não sendo por isso de estranhar o seu recorte maleável (Sousa, 2017). 
Quem discursa, pretende persuadir o outro, para além de ter em mente a imposição da sua própria opinião (Arendt, 1958/1998). O que nos leva à argumentação, que tem por base a ideia de convencer, de persuadir e que remete a origem do discurso político para a Grécia Antiga.

Para Michel Maffescoli, o político pertence à categoria das coisas que perduram em todas as épocas que são, ao mesmo tempo, "sempre diferentes" (Maffesoli, 1992/2005: 23). Já Michel Foucault refere que o discurso não é apenas a tradução das lutas ou sistemas dominantes, mas relaciona-se com as relações entre indivíduos (Foucault, 1970/1999: 10), sendo que o político assume no seu discurso uma dicotomia entre o seu posicionamento ideológico e a sua prática política, que nem sempre são coincidentes.

Ole Risse (2000) e Thomas Waever (2004) chamam à atenção para que o discurso político possa ser encarado enquanto uma realidade dialógica e, nesse sentido, contribuir para a formação de um imaginário próprio podendo, no entanto, também ser visto através da ideologia que emana. Partindo do princípio de que a formação do imaginário político não é inocente, estando associado inevitavelmente a essa ideologia, pelo que deve ser entendido para explicar a ordem social, as condições de vida as relações humanas (Fiorin, 1998). Essa dimensão ideológica do discurso, tanto pode transformar como reproduzir as relações de poder. Ao contrário de Marx e Engels (1846/2001: XXI-XXIII), que associavam a ideologia à "falsa consciência" ou a um qualquer sistema de ideias, Gramsci, por exemplo, olha para ela enquanto "a própria conceção do mundo, que se manifesta na ação e a organiza" (Gramsci, 1978: 22).

Pierre Bourdieu desenvolveu nos anos 1970 uma proposta metodológica que promove um corte com uma tradição assente unicamente nos sentidos dos discursos, remetendo o investigador para lá do que as palavras queriam dizer e que ficou plasmado no livro Ce que parler veut dire [O que falar quer dizer] (1982). Sejam proferidos por parlamentares, por um primeiro-ministro ou por um presidente da República, os discursos políticos são sempre encenados. É o denominado "discurso compatível", que faz perceber a razão pela qual Michel Foucault sublinhou que a verdade "não existe fora do poder", o que não quer dizer que ela seja um mito, já que a verdade "é deste mundo" e é nele produzida "graças a múltiplas coerções e nele produz efeitos regulamentados de poder" (Foucault, 1975/2010, p. 12).

\section{0 luso-tropicalismo e a 'portugalidade'}

O luso-tropicalismo é um modelo social da autoria do sociólogo brasileiro Gilberto Freyre, que diferencia a colonização portuguesa da dos demais impérios europeus por ser, alegadamente, mais "benigna". Foi sustentado em pressupostos históricos, na tradição e no alegado "carácter dos portugueses", através de lugares-comuns, servindo de suporte científico, através da "mística luso-cristã de integração" (Freyre, 1953; 1961), para o desenvolvimento da política do Estado Novo, assumindo-se como a verdadeira evidência da alegada "particular maneira portuguesa de estar no mundo" (Castelo, 2011).

O colonialismo português diferenciava-se, assim, por assentar na empatia e na afeição com os indígenas, na 'portugalidade', que decorria "dos contactos prolongados que os portugueses mantiveram com culturas distintas (...) e do efeito que isso teria tido numa espécie de multiculturalidade indissociável de cada português" (Sousa, 2020, s.p.). O que, na prática, tinha uma configuração totalmente diferente, com um recorte de interculturalidade invertida (Stoer \& Cortesão, 1999). O que não seria de estranhar, uma vez que a propaganda do regime dava a conhecer uma realidade não existente, contrariada pela legislação vigente, como no caso da "Carta Orgânica do Império Colonial Português", de 1937 (República Portuguesa, 1945), que obrigava todas as autoridades e, nomeadamente, os colonos, a patrocinarem iniciativas destinadas a civilizar os indígenas, de acordo com os valores da "pátria portuguesa", o que se desviava do luso-tropicalismo de Freyre, que propalava uma igualdade no relacionamento entre o colono e o indígena (Sousa, 2020).

Foi já na sequência do novo quadro político internacional saído da II Guerra Mundial e da necessidade de o Governo português sublinhar que o seu território se estendia "Do Minho a Timor" - como ficou fixado no slogan então adotado, "Portugal do Minho a Timor" (sendo que Timor e os territórios que ficavam no então ultramar, seriam províncias do país, 
tal como as que existiam dentro das suas fronteiras), tentando garantir que as colónias não eram territórios autónomos, pelo que não fazia sentido a sua autodeterminação que, a partir da década de 1950, o regime adotou uma versão simplificada e nacionalista do luso-tropicalismo como discurso oficial, para ser utilizado na propaganda e na política externa (Sousa, 2017).

A alegada especificidade do carácter português, patente na sua predisposição para a aventura ultramarina, para a miscigenação, para a interpenetração cultural; para a influência do contacto com outras etnias, desde os primórdios da nacionalidade; para além do papel do cristianismo português na colonização híbrida dos trópicos, são as características em que é sustentada a teoria de Freyre. Características que não deixam de ser psicoculturais e que o sociólogo brasileiro associa ao português, enquanto características que lhe seriam inatas e estariam presentes em qualquer tempo e lugar. O que não deixa de levantar muitas dúvidas, já que as identidades não são reificadas, pelo que atribuir determinadas características ao português, não deixa de ser redutor. No livro O mundo que o português criou (1953), Freyre alarga o seu campo de pesquisa do Brasil a todas as áreas de colonização portuguesa, que considera formarem uma unidade de sentimento e cultura, salientando o lugar singular do mestiço no "mundo português", devido à atitude positiva dos progenitores portugueses relativamente aos filhos mistos, e que era única num povo europeu.

Foi, de resto, neste período (décadas de 50 e 60 do século $X X)$ que foi cunhado o conceito de 'portugalidade', numa estratégia que ia no sentido de combater os movimentos independentistas que emergiam nas antigas colónias, defendendo a pertença desses territórios a Portugal, por via do seu "destino histórico" (Franco, 2000). Esse facto seria sublinhado no discurso político da 'portugalidade', com a assunção de Portugal, como um país uno e indivisível, através do slogan já referido: "Portugal do Minho a Timor" (Sousa, 2017).

A este propósito, Cláudia Castelo refere que o estudo de receção do luso-tropicalismo em Portugal dá uma ajuda na perceção de como as ideias de Gilberto Freyre "ainda ecoam no atual discurso político e cultural". E, muito embora já não estejam ligadas diretamente ao colonialismo, estão-lhe subjacentes, servindo agora "para justificar a criação formal de uma comunidade lusófona com propósitos culturais, económicos e de cooperação em matéria de política externa" (Castelo, 2011, p. 140). Adverte, assim, que o risco atual reside no facto de o conceito continuar a ser usado de forma acrítica e imobilista. E, se, no passado, serviu para legitimar o colonialismo português, hoje, é utilizado para dar corpo ao "mito da tolerância racial dos portugueses e até de um nacionalismo português integrador e universalista, em contraponto aos 'maus' nacionalismos, fechados, etnocêntricos e xenófobos" (Castelo, 2013, s. p.).

\section{Metodologia}

A metodologia adotada neste estudo é compósita, assentando numa amostragem não probabilística, em que as comparações não apresentam fundamentação matemática ou estatística, dependendo unicamente da escolha efetuada por quem desenvolveu a investigação. É devido a esse constrangimento que não se podem generalizar os resultados obtidos com precisão estatística, não obstante o exercício, pelo seu grau de complexidade reduzido, levante poucas dúvidas em relação às leituras que permite. A amostra foi intencional e desenvolvida mediante observação direta do investigador, no pressuposto de que este dispunha sobre o universo conhecimento e a necessária intuição de investigação (Pardal \& Lopes, 2011; Quivy \& Campenhoudt, 2008).

Foi desenvolvida uma amostragem por conveniência, e uma recolha de dados através de documentação indireta, assente na pesquisa de conteúdos publicados na página oficial da Presidência da República portuguesa (https://www.presidencia.pt/), entre discursos do presidente da República, notícias da sua ação política e notas informativas, durante o seu primeiro mandato (entre 9 de março de 2016 e 8 de março de 2021) - cinco evidências -, para além de uma pesquisa de notícias e de artigos de opinião nos média (tradicionais e online) sobre e de autoria do presidente da República (23 evidências), num total de 28 conteúdos (ver Tabela 1), no intuito de recolher marcas do luso-tropicalismo nas intervenções do chefe de Estado. Foi, também, utilizada alguma 
análise de conteúdo, assente numa hermenêutica controlada por intermédio da inferência, oscilando entre a objetividade e a subjetividade (Bardin, 2018).

\section{Discussão e resultados}

Marcelo Rebelo de Sousa tomou posse como presidente da República portuguesa a 9 de março de 2016, sucedendo a Cavaco Silva, que cumpriu dois mandatos de cinco anos cada um. Este professor universitário da área do Direito, teve sempre uma forte presença nos média, desde os tempos da ditadura do Estado Novo, derrubada através da Revolução do 25 de Abril de 1974.

A expectativa era grande, em Portugal, com a eleição do novo presidente da República, independentemente de quem fosse eleito, já que a Presidência de Cavaco Silva, ficara marcada por um distanciamento com o povo. Cavaco sempre se mostrou distante e, de certa forma, inalcançável por parte dos portugueses, marcando desde logo uma barreira que nunca foi transponível. O que não deixa de ser curioso, contrastando, de certa forma, com as campanhas eleitorais do PSD que o levariam a primeiro-ministro por duas vezes e, mesmo, as que o levaram à Presidência da República.

Na observação que fez dos discursos políticos proferidos por Cavaco Silva (2006-2014), o investigador Miguel Cardina evidencia como a "memória oficial" tem vindo a acionar certas narrativas sobre o passado apontando "para a persistência de um imaginário de traços coloniais num espaço-tempo pós-colonial", numa narrativa que embora não seja nova, reproduz um conjunto de tópicos de matriz "Iusotropicalizante" (Cardina, 2014, s.p.). Não é, por isso, de estranhar que Alexandra Lucas Coelho, num artigo de opinião que assinou e que intitulou, "A pele de Cavaco e os milagres de Marcelo", mostra o seu regozijo pela saída de Cavaco e pela consequente entrada em cena de um novo presidente, no caso, Marcelo Rebelo de Sousa: "Portugal largou Cavaco como se mudasse de pele. Nenhuma transição desde o fim da ditadura gerou este alívio, quase uma libertação nacional" (Coelho, 2016, p. 45). Mas, logo após o discurso de tomada de posse, a escritora admite ter-se enganado, assinalando que "enquanto alguém quiser o pastiche de uma nau ou um museu para 'celebrar os Descobrimentos' não teremos avançado", continuando Portugal "a repetir os velhos mitos que o confortam e adiam, ora desconfiado, ora ufano, nunca mudando o ponto de vista" (Coelho, 2016, p. 45).

De facto, logo na cerimónia de tomada de posse, Marcelo Rebelo de Sousa evoca passagens da denominada "história mítica de Portugal", onde pontificam, por exemplo, o "Milagre de Ourique", ou as "Cortes de Lamego", que Alexandre Herculano desmontou no século XIX mas que, anos depois, o Estado Novo recuperou e não se cansou de disseminar, através da sua propaganda, enquanto mistos de origem do país: "Aqui se criaram e sempre viverão comigo aqueles sentimentos que não sabemos definir (...). Amor à terra, saudade, doçura no falar, comunhão no vibrar, generosidade na inclusão, crença em milagres de Ourique, heroísmo nos instantes decisivos" (Presidência da República, 2016, s.p.). O mesmo aconteceu com as figuras de Viriato e de Nun'Álvares Pereira, tornados símbolos da 'portugalidade' e da independência nacional pela ditadura fascista. $\mathrm{O}$ que não terá sido por acaso, sabendo-se que Marcelo conhecia bem o modus operandi dos média, nomeadamente a forma como se passam mensagens com destinatários definidos, numa lógica que se aproxima da comunicação estratégica (Aronczyk, 2013).

Para o historiador Diogo Ramada Curto, o facto de Marcelo Rebelo de Sousa convocar toda essa parafernália mítica constituiu um somatório de "'referências obsoletas, para não lhes chamar bacocas", fazendo um reparo em relação à invocação de Mouzinho de Albuquerque ("um herói português do século XIX"), ex-governador de Moçambique, conhecido pelo seu recorte sanguinário, lembrado que ele terá dito que "que este reino [Portugal] é obra de soldados": "Imagino como terá sido entendida, pelo Presidente de Moçambique, a frase (...) de Mouzinho de Albuquerque, que capturou Gungunhana em Chaimite (Gomes, M. \& Crisóstomo, 2016, p. 6.

No dia 29 do mesmo mês, à Rádio Renascença, o presidente da República, recuperava a frase "viver habitualmente", que decorre da expressão latina aurea mediocritas e que quer dizer viver feliz com o pouco que se tem (Marinheiro, 2008, s.p.), que está associada ao Estado Novo e que o historiador Fernando 
Rosas, apelidou de "mito da pobreza honrada" (Rosas, 2001, p. 1035). Segundo Marcelo, Portugal, em março de 2016, seria menos "crispação" e mais "estabilidade", entendendo, por isso, existir "um clima mais descrispado, mais sereno, mais calmo na vida portuguesa e é este viver de uma forma habitual naquilo que eu chamo estabilidade (...) é bom para o país" (Rádio Renascença, 2016, s.p.).

Num artigo de opinião assinado no Jornal de Negócios, o presidente da República é coerente com o seu discurso de tomada de posse, sustentando o alegado recorte diferenciador e único dos portugueses - em que navega o luso-tropicalismo -, ao assinalar ser sua tarefa "conhecer a História e as suas lições, saber que somos dos melhores em vocação universal, em pontes entre culturas, civilizações e continentes, por geografia, mar, língua, comunidades espalhadas pelo mundo, aptidão invulgar para apreender e incluir" (Sousa, 2016, s.p.). Evocava os 900 anos de História de Portugal, acrescentando mais recortes psicológicos do povo, como o facto de ser indomável, numa ideia atribuída ao líder romano Júlio César em que salientava existir nos confins da Ibéria um povo que não se governava nem se deixava governar. Não obstante, referia que "a nossa única sorte é termos nascido portugueses!" (Sousa, 2016, s.p.).

Na sua primeira comemoração de um 10 de Junho enquanto presidente da República, fez regressar a habitual parada militar ao Terreiro do Paço (Lisboa), onde nunca voltara desde os tempos da ditadura, em que servia de palco das comemorações do Dia da Raça entre 1963 e 1973. Não sendo, em si, um ato eivado de luso-tropicalismo, o facto é que o presidente logo se aprestou a sublinhar o alegado caráter diferenciador dos portugueses, o que sempre acontece que há comemorações do Dia de Portugal. Para Marcelo, o Terreiro do Paço concentra em si os factos mais importantes da História de Portugal, mesmo antes das "Descobertas": "Aqui se misturaram gentes, culturas e produtos, vindos por terra ou trazidos por naus e caravelas dos lugares mais longínquos que fomos descobrindo (...). O nosso cosmopolitismo começou aqui" (Lopes, 2016, p. 6).

Marcelo Rebelo de Sousa inaugurou uma nova forma de assinalar o Dia de Portugal, com cerimónias em Portugal e num país estrangeiro. Assim, em Pa- ris (França), capital europeia onde foram acolhidos muitos portugueses, lembrou as vagas de emigração para França nas décadas de 50, 60 e 70, em plena ditadura, portanto, feita "em situação de pobreza, para trabalhos duros". Rematou, afirmando que "aqueles que aqui estão são dos melhores de nós" (Botelho, 2016, p. 4).

Já no seu elogio fúnebre a Mário Soares (10 de janeiro de 2017), reputou o ex-presidente da República de humanista, afirmando que ele tinha sido "um construtor de portugalidade". Uma afirmação proferida, mesmo tendo em conta que Soares tinha sido um dos que estiveram na linha da frente para derrubar o Estado Novo e, consequentemente, a correspondente 'portugalidade' em que ele assentava, tendo pago caro essa ousadia, nomeadamente através da deportação e do exílio. No discurso, com pouco mais de sete minutos, Marcelo Rebelo de Sousa utiliza oito vezes a palavra 'portugalidade'. Começa, desde logo, por sublinhar o sítio onde se realizava a cerimónia - o Mosteiro dos Jerónimos - catalogando-o de "inspirador", reportando-o ao tempo da expansão portuguesa. O que serve de introdução a uma 'portugalidade' que Marcelo Rebelo de Sousa associa ao ex-presidente da República, muito embora a recontextualize, mas deixando-a associada ao alegado ecumenismo imperial português:

E também o humanismo e a portugalidade. (...) Portugalidade na nossa capacidade de ir e de voltar, trazendo à Europa o que ela desconhecia. Humanismo e portugalidade. (...) O humanismo que definiu Mário Soares. (...) Porque de um humanismo situado, combatente, militante se tratava no afã de refazer Portugal. Portugal, princípio e fim de um percurso que, para Mário Soares, era um desígnio. Mas um desígnio aberto. (...) Aberto ao universo, sem limites físicos ou espirituais, ao melhor jeito da nossa portugalidade. Uma portugalidade ambiciosa, generosa, fraternal, franqueada a tudo e a todos. É certo que diversa da portugalidade de outros que sendo igualmente ecuménicos teriam esperado um Império imorredouro. Antes portugalidade lida à luz do realismo dos novos contextos e da liberdade dos povos. Foi assim Mário Soares. À sua maneira, no seu tempo e no seu modo, um singular humanista e construtor de portugalidade (Presidência da República, 2017, 10 de janeiro, s.p.).

Sublinha que na morte de Mário Soares há "uma saudade feita futuro", numa alocução que remete 
para os escritos do Padre António Vieira, de Fernando Pessoa e de Agostinho da Silva, que perspetivam Portugal através do futuro, numa lógica messiânica, muito em voga no Estado Novo (Sousa, 2017, p. 390).

Num outro registo, ligado à passagem dos 16 anos da tragédia da queda da Ponte Hintze Ribeiro, em Entre-os-Rios, em que morreram 59 pessoas, o chefe do Estado disse que Portugal apresenta "uma identidade nacional como poucos têm em todo o mundo" (Rádio Renascença, 2017, s.p.), como que a corresponder a Eduardo Lourenço (1994), que sustentou que Portugal tinha uma hiperidentidade, para compensar através do imaginário o seu deficit de identidade real. Restando saber a forma em como a identidade nacional se relaciona com aquele tipo de tragédia.

No balanço da sua visita de Estado ao Senegal, durante a qual esteve na ilha de Gorée, antigo entreposto do tráfico de escravos, o chefe de Estado recuperou a sublinhada identidade dos portugueses, considerando que "Portugal tem no mundo, de facto, um acolhimento singular", e os portugueses "não têm razão para ter uma autoestima muito pequena". O que configura "uma característica secular nossa, mas que está presente hoje. É um trunfo na política internacional" (Comunidades Lusófonas, 2017, s.p.). $\mathrm{Na}$ oportunidade, o presidente reconheceu a injustiça da escravatura, lembrando que Portugal a aboliu em 1761. Motivou, no entanto, o lançamento de uma petição que ia no sentido de que Portugal devia pedir desculpas por ter sido esclavagista, à semelhança do que fez o papa João Paulo II, quando visitou o mesmo local, e que originou um debate crispado nos média portugueses.

Em plena sessão solene da Revolução do 25 de Abril, o presidente leva ao extremo a retórica sobre a hiperidentidade portuguesa, misturando conceitos contraditórios ao referir-se a um alegado recorte português, assente num "nacionalismo patriótico de vocação universal e não um nacionalismo egocêntrico agarrado a um pretenso passado (...) e insusceptível de enfrentar o futuro. Aliás, o único que perfilhamos capaz" (Presidência da República, 2017, 25 de abril). Como se o patriotismo pudesse, alguma vez, estar associado ao nacionalismo...
Já no Dia de Portugal de 2017, comemorado no Porto e no Brasil, observou que o passado, mesmo quando não foi sinónimo de felicidade, "foi a nossa garantia, o presente é a nossa exigência, o futuro é o nosso destino". De novo, uma visão teleológica a pontuar o discurso do presidente. Na oportunidade, referiu-se às comunidades portuguesas, reportando-as a um "outro Portugal que nos faz universais". Simbolicamente, por esses dias, promulgava o diploma do governo de regulação do acesso à nacionalidade portuguesa por parte dos netos de portugueses nascidos no estrangeiro (Sá, 2017, s.p.)

Através de uma nota deixada no portal da Presidência da República referia que, como presidente da República, era com profundo regozijo que saudava Manuel Alegre pelo seu doutoramento "honoris causa" pela Universidade de Pádua. Aproveitava o ensejo para "exortar os Portugueses a ler, estudar e desfrutar da obra notável deste cidadão e poeta que nos restitui o sentido da portugalidade e o seu universalismo" (Presidência da República, 2017, 29 de novembro, s.p.). Uma nota com sentido, uma vez que Manuel Alegre, pertencendo ao Partido Socialista, da esquerda parlamentar, portanto, sempre se mostrou um cultor da 'portugalidade', fazendo mesmo questão de a conceptualizar ao sublinhar a sua vocação humanista e antirracista (Sousa, 2017), o epítome, afinal, do luso-tropicalismo.

A ideia principal da mensagem de ano novo (2018) do presidente da República foi a necessidade de "reinventar Portugal". Num ensaio publicado no jornal Público, o filósofo José Gil questiona o timing e o porquê desse apelo. Nomeadamente por ter sido feito por parte de alguém com um recorte "realista", mas que propunha um tipo de ideal, aparentemente irrealizável, num discurso quase messiânico (sem Messias) e proto-nacionalista. É que, no entendimento de Gil, este discurso estava amarrado a um passado bem definido: "Obedece à lógica ancestral dos discursos de salvação (messiânicos, ou nacionalistas, evangélicos, terapêuticos, populistas)", sendo que "a nossa sociedade não está doente nem ameaçada", nem tem "inimigos nem precisa de um líder carismático; nem de anunciar a vinda de um 'homem novo', de um "novo português'” (Gil, 2018, p. 6). O filósofo assinala que a mensagem do presidente assenta 
numa "lógica da salvação, em que o futuro retomará o passado glorioso, resgatando o presente doente, minado por um inimigo (...) através do sacrifício" (Gil, 2018, p. 6).

O 10 de junho de 2018 foi assinalado em Ponta Delgada (Açores) e em Boston (EUA). Marcelo Rebelo de Sousa privilegiou a exaltação nacional, utilizando a letra do hino: "Heróis do mar que rasgámos, Nobre povo que resistiu a tudo e a tudo resiste". Sublinhou ainda a riqueza na diversidade - "um só Portugal, feito de muitos portugais que podem e devem ser diversos" - e elogiou a autonomia regional. Disse ainda preferir "o multilateralismo realista do que o unilateralismo revivalista" (Rodrigues, 2018, p. 6). Entre milhares de luso-descendentes durante as comemorações, em Boston, deixava claro que "os Estados Unidos da América são um grande país, mas Portugal ainda é maior. Temos o maior país do mundo" (Expresso, 2018). A Presidência da República dava nota no seu portal que, no final do cortejo de tochas, e já no arraial português em Rhode Island, durante o Festival WaterFire e o encontro com a Comunidade Portuguesa, "todas as tochas juntas acederam a chama da portugalidade". De novo, a associação ao Dia de Portugal a um conceito datado, como vimos, tal como o fizera o antecessor de Marcelo, Cavaco Silva que ligou a termo ao Dia da Raça, que se assinalava no período da ditadura, no mesmo dia.

A propósito dos discursos oficial do Dia de Portugal, a coordenadora do Bloco de Esquerda (BE), Catarina Martins, reagia no Twitter, lamentando não se ter lamentado a violência da expansão portuguesa, nomeadamente, a escravatura que lhe está associada: "Virá o dia em que os discursos oficiais serão capazes de reconhecer a enorme violência da expansão portuguesa, a nossa história esclavagista, a responsabilidade no tráfico transatlântico de escravos" (Lopes, 2018 , s.p.). Na resposta, o historiador Rui Ramos, assinava um artigo de opinião no Observador, em que salientava não haver nada de novo no discurso da líder do $\mathrm{BE}$, ironizando com uma pergunta sobre se o 10 de Junho deveria ou não ser "um dia de vergonha e de penitência nacional - não o dia de Portugal, mas o dia contra Portugal?" (Ramos, 2018, s.p.).

O presidente da República condecorava, no dia 29 de janeiro, o cónego João Seabra, seu amigo de infância, fazendo referência à sua experiência como assistente nacional do Movimento Comunhão e Libertação. Na oportunidade, aludiu à "portugalidade" ligada a uma vocação universal (Martins, 2019, s.p.).

Através de um artigo de opinião de José Pinto, publicado no Observador, referia que a visita de Marcelo Rebelo de Sousa a Angola estava a ser pautada por sucessivos banhos de multidão. Segundo o articulista, esses banhos de multidão não traduziam o estado das relações entre Portugal e Angola lembrando, no entanto, imagens que traziam à memória outras imagens, datadas de 1969, relativas a uma outra visita, a de Marcello Caetano, mostrando milhares de angolanos a encheram as ruas para aplaudir o então Presidente do Conselho: "Para o regime então vigente era a portugalidade a encher as ruas de Luanda. (...) Muitos desconheciam ou recusavam a definição de portugalidade. Limitavam-se a dar corpo à forma angolana de estar na vida" (Pinto, 2019, s.p.).

Numa visita às instalações da Bosch, em Braga. Marcelo dava largas a toda a sua hiperidentidade, ao referir-se assim aos portugueses: "Não somos nós os melhores dos melhores do mundo? Com todo o respeito pelos nossos amigos alemães e também espanhóis, (...) somos os melhores, (...) não admira que aqui estejam os melhores a fazer o melhor. (Observador, 2019, s.p.).

O Dia de Portugal de 2019 foi passado em Portalegre e em Cabo Verde. Ainda em território português, o presidente exortou a existência de "uma pátria sem complexos pelo passado, na construção do presente e na armação do futuro, num conjunto de vários portugais muito para além das fronteiras geográficas" (Ribeiro, 2019, p. 8). Recorrendo ao que apelidou de "complexo muito nacional" como um dos traços do nosso pessimismo, que disse não apreciar por considerar primário ou exorbitante, contrapôs com a repetição da ideia de que "quando somos muito bons, somos dos melhores dos melhores" (Ribeiro, 2019, p. 8). Retomou o conceito de "território espiritual" e que está na origem destas comemorações desde o início do seu mandato.

O historiador Vasco Pulido Valente, no jornal Público, referia-se ao dia 13 de janeiro de 2020, como aquele em que Marcelo tinha dito em Moçambique 
que Portugal "precisava de estar mais na moda do que está". Não sabendo a forma de como isso se iria operacionalizar, antecipava "uma nova época de louvaminhas ao antigo império colonial". Frisava, porém, já estarmos suficientemente longe de Salazar para nos podermos permitir estas brincadeiras, vaticinando que o presidente Marcelo iria ter muito com que se entreter: "É só isso que ele quer e esta é a única maneira como consegue pensar" (Valente, 2020, p. 7).

No 10 de junho, por causa da pandemia da Covid-19, realizou-se uma cerimónia simbólica em frente ao Mosteiro dos Jerónimos (Lisboa), tendo as comemorações previstas na Madeira sido adiadas para 2021, o mesmo acontecendo em relação à ida até à África do Sul. No último discurso do seu mandato no Dia de Portugal, o presidente da República lançou um desafio ao país: "É a altura de 'acordar' para a mudança necessária" (Botelho, 2020, 11 de junho, p. 10).

Com a vandalização da estátua do Padre António Vieira, em Lisboa, a estar na ordem do dia, o que tinha sido aplaudido por parte daqueles que sempre disseram que a estátua era anacrónica pois, tendo sido inaugurada em 2017, mostrava Vieira rodeado de pequenos índios, o que evidenciava um paternalismo associado à época colonial portuguesa. Em sentido contrário, manifestaram-se a favor da estátua algumas forças de extrema-direita. O presidente da República também falou sobre o assunto, mostrando-se contra a vandalização e destruição de estátuas, em geral. Defendeu que a história deve ser assumida como um todo, referindo-se em particular à estátua de Vieira. Considerou ainda que Portugal tem sectores racistas e xenófobos, mas defendeu que a maneira de lutar contra as discriminações "não é estar a destruir história, é fazer história diferente" (Lusa e Borges, 2020, s.p.).

No dia em que foi entrevistado no canal público de televisão (RTP1), depois de o primeiro-ministro lhe ter proposto que decretasse o estado de emergência com carácter preventivo por causa da Covid-19, Marcelo Rebelo de Sousa utilizou aquele palco para protagonizar, não utilizando a costumeira "comunicação ao país". Num sistema semipresidencialista como é o português, chamou a si os erros do com- bate à pandemia, como se fosse chefe do executivo. Projetou-se, assim, simbolicamente acima do Governo, "como uma espécie de 'pai da pátria"' (Almeida, 2020, p. 18).

A 7 de dezembro de 2020, Marcelo Rebelo de Sousa anunciava a sua recandidatura ao cargo de presidente da República. Fê-lo perto do Palácio de Belém (Lisboa), a sua residência oficial, numa pequena pastelaria, que nem espaço tinha para albergar todos os jornalistas. "É o retrato dos tempos de restrições em que vivemos", justificava (Botelho, 2020, 8 de dezembro, p. 2). Apresentou-se com as cores nacionais, mas como um homem só. Na primeira candidatura tinha sido igual, só mudando o espaço escolhido. Disse ser o mesmo de sempre e aquele que os portugueses conhecem, com a mesma visão do país, mas uma nova missão: ajudar a "refazer Portugal" da crise pandémica. Aproveitou para fazer o seu autorretrato, voltando ao argumentário conhecido ao longo do mandato: "Orgulhosamente português e por isso universalista. Convictamente católico e por isso dando primazia à dignidade da pessoa, ecuménico e contrário a um Estado confessional" (Botelho, 2020, 8 de dezembro, p. 2). Sobre Portugal, voltou a dizer tratar-se de um país que é uma "plataforma de culturas, civilizações, oceanos e continentes" (Botelho, 2020, 8 de dezembro, p. 2). O relato da jornalista do Público, refere que Marcelo "saiu a pé, rodeado de jornalistas que se atropelavam procurando, agora, uma palavra fora da caixa. Sem sucesso" (Botelho, 2020, 8 de dezembro, p. 2). Sendo Marcelo um homem dos média, terá representado um guião, devidamente ponderado, mesmo que tudo tenha aparentemente sido improvisado. 
Tabela 1 - Discursos e outras intervenções de Marcelo Rebelo de Sousa no seu primeiro mandato de Presidente da República [2016-2021] no portal da Presidência da República e nas notícias/artigos de opinião saídos nos média com um recorte luso-tropicalista. Produção do autor.

\begin{tabular}{|c|c|c|}
\hline Título/Assunto & Fonte & Data \\
\hline $\begin{array}{l}\text { Discurso de Tomada de Posse do Presidente } \\
\text { da República }\end{array}$ & $\begin{array}{l}\text { Presidência da República } \\
\text { http://www.presidencia.pt/?idc=22\&idi=103410 }\end{array}$ & $9-3-2016$ \\
\hline As notas ao discurso de Marcelo & $\begin{array}{l}\text { Público } \\
\text { p. } 6\end{array}$ & $10-3-2016$ \\
\hline $\begin{array}{l}\text { A pele de Cavaco e os milagres de Marcelo } \\
\text { (Opinião de Alexandra Lucas Coelho) }\end{array}$ & Público, p. 45 & $13-3-2016$ \\
\hline $\begin{array}{l}\text { Portugal, Março de 2016, segundo Marcelo: } \\
\text { menos "crispação", mais "estabilidade" }\end{array}$ & $\begin{array}{c}\text { Rádio Renascença } \\
\text { http://rr.sapo.pt/printArticle.aspx?objid=d969fea1-acf5-e- } \\
\text { 511-b837-0022640e86b7 }\end{array}$ & $29-3-2016$ \\
\hline $\begin{array}{l}\text { Portugal, uma Pátria feita contra a sorte } \\
\text { (Opinião, Marcelo Rebelo de Sousa) }\end{array}$ & $\begin{array}{l}\text { Jornal de Negócios } \\
\text { http://www.jornaldenegocios.pt/opiniao/detalhe/marcelo_ } \\
\text { rebelo_de_sousa_portugal_uma_patria_feita_contra_a_sor- } \\
\text { te.html }\end{array}$ & $30-5-2016$ \\
\hline $\begin{array}{l}\text { Dia de Portugal: Marcelo elogiou um povo } \\
\text { melhor do que as suas elites }\end{array}$ & $\begin{array}{l}\text { Público } \\
\text { pp. 2, 4-8 }\end{array}$ & $\begin{array}{l}11-10- \\
2016\end{array}$ \\
\hline $\begin{array}{l}\text { Homenagem ao Presidente Mário Soares. } \\
\text { Mosteiro dos Jerónimos }\end{array}$ & Presidência da República http://tinyurl.com/k4clh6v & $10-1-2017$ \\
\hline $\begin{array}{l}\text { Marcelo homenageou memória das vítimas } \\
\text { de Entre-os-Rios }\end{array}$ & $\begin{array}{l}\text { Rádio Renascença } \\
\text { http://rr.sapo.pt/noticia/77591/marcelo_homenageou_me- } \\
\text { moria_das_vitimas_de_entre_os_rios }\end{array}$ & $4-3-2017$ \\
\hline $\begin{array}{l}\text { 'Portugueses são admirados em todo o } \\
\text { mundo, não têm inimigos' }\end{array}$ & $\begin{array}{l}\text { Comunidades Lusófonas } \\
\text { https://comunidadeslusofonas.pt/portugueses-sao-admira- } \\
\text { dos-em-todo-o-mundo-nao-tem-inimigos/ }\end{array}$ & $14-4-2017$ \\
\hline $\begin{array}{c}\text { Sessão Solene Comemorativa do } 43.0 \\
\text { Aniversário do } 25 \text { de Abril (Assembleia da } \\
\text { República) }\end{array}$ & $\begin{array}{l}\text { Presidência da República } \\
\text { http://www.presidencia.pt/?idc=37\&idi=126919 }\end{array}$ & $25-4-2017$ \\
\hline $\begin{array}{l}\text { Dia de Portugal comemorado sob o signo da } \\
\text { unidade nacional }\end{array}$ & $\begin{array}{l}\text { Público } \\
\text { pp. 8-9 }\end{array}$ & $11-6-2017$ \\
\hline $\begin{array}{c}\text { Em } 5 \text { minutos, Marcelo fez várias declara- } \\
\text { ções de independência }\end{array}$ & $\begin{array}{l}\text { Diário de Notícias } \\
\text { http://www.dn.pt/portugal/interior/em-5-minutos-marce- } \\
\text { lo-fez-varias-declaracoes-de-independencia-8554781.html }\end{array}$ & $11-6-2017$ \\
\hline $\begin{array}{l}\text { Presidente da República felicita o escritor e } \\
\text { poeta Manuel Alegre pelo seu doutoramento } \\
\text { «honoris causa» pela Universidade de Pádua }\end{array}$ & $\begin{array}{c}\text { Presidência da República } \\
\text { https://www.presidencia.pt/atualidade/toda-a-atualida- } \\
\text { de/2017/11/presidente-da-republica-felicita-o-escritor-e-po- } \\
\text { eta-manuel-alegre-pelo-seu-doutoramento-honoris-causa- } \\
\text {-pela-universidade-de-padua/ }\end{array}$ & $\begin{array}{l}29-11- \\
2017\end{array}$ \\
\hline $\begin{array}{c}\text { "Reinventar Portugal" - Sobre um discurso } \\
\text { quase messiânico (sem Messias), ensaio de } \\
\text { José Gil }\end{array}$ & $\begin{array}{l}\text { Público, } P 2 \\
\text { p. } 6\end{array}$ & $7-1-2018$ \\
\hline
\end{tabular}




\section{Presidência da República}

Festival WaterFire e encontro com a Comunidade Portuguesa de Rhode Island

https://www.presidencia.pt/atualidade/toda-a-atualidade/2018/06/festival-waterfire-e-encontro-com-a-comunida-

$10-6-2018$ de-portuguesa-de-rhode-island/

Marcelo adverte para "volúpia das rupturas", Costa desvaloriza

Público

p. 6

$11-6-2018$

Expresso online https://expresso.pt/opiniaoeblogues/es-

Está dito tadito/2018-06-11-Os-Estados-Unidos-da-America-sao-um-grande-pais-mas-Portugal-ainda-e-maior.-Temos-o-maior-

$11-6-2018$ -pais-do-mundo

noticiasaominuto.pt

"Podia ser num 10 de Junho, mas não foi". O tweet polémico de Catarina

https://www.noticiasaominuto.com/politica/1027270/ podia-ser-num-10-de-junho-mas-nao-foi-o-tweet-polemico-de-catarina

Observador

10 de junho_Um dia contra Portugal? (Opinião, Rui Ramos)

https://observador.pt/opiniao/um-dia-contra-portugal/

\section{Rádio Renascença}

Marcelo condecorou o cónego João Seabra, um apaixonado pela educação

https://rr.sapo.pt/noticia/139206/marcelo-condecorou-o-

29-1-2019 -conego-joao-seabra-um-apaixonado-pela-educacao

\section{Observador}

Marcelo e os banhos de multidão: a história revisitada (Opinião, José Pinto)

https://observador.pt/opiniao/marcelo-e-os-banhos-de-

$10-3-2019$ -multidao-a-historia-revisitada/

\section{Observador}

Marcelo diz que portugueses são "os meIhores dos melhores do mundo"

https://observador.pt/2019/03/22/marcelo-diz-que-portu22-3-2019 gueses-sao-os-melhores-dos-melhores-do-mundo/

Público

Marcelo pede no 10 de Junho exigência ética na vida pública

pp. 8-11

$11-6-2019$

Público

p. 7

$18-1-2020$ Valente)

Público

p. $10-11$

Marcelo e o 10 de Junho: Este é o "tempo

de acordar" para a mudança necessária

Público

Marcelo: é "verdadeiramente imbecil" vandalização de estátua do padre António Vieira

https://www.publico.pt/2020/06/15/politica/noticia/mar-

$15-6-2020$ celo-verdadeiramente-imbecil-vandalizacao-estatua-padre-antonio-vieira-1920606

Marcelo Rebelo de Sousa inaugurou o presidencialismo simbólico (Opinião São José Almeida)

Público

p. 18

Público

pp. 2-4 


\section{Conclusões}

É do lado da política que ciclicamente é invocada a 'portugalidade' associada, como vimos, ao luso-tropicalismo, teoria de Gilberto Freyre apropriada pelo Estado Novo, e que ainda hoje vive amarrada à retórica que lhe esteve na origem. Esta tendência verifica-se nos discursos dos últimos dois presidentes da República portugueses, tendo começado com Cavaco Silva, e continuado com Marcelo Rebelo de Sousa, que lhe sucedeu no cargo.

Qual o sentido que a 'portugalidade' tem hoje? Será que o ideário luso-tropicalista em que foi cunhada pode ser a sua melhor tradução? Mesmo que hoje seja menos plausível a existência de particularismos dos povos, e não haja lugar para qualquer espécie de 'portugalidade', o termo é cada vez mais utilizado, nomeadamente através da Comunicação Estratégica.

E, mesmo que Marcelo Rebelo de Sousa pareça querer associar a 'portugalidade' e a dinâmica discursiva luso-tropical ao patriotismo, logo a liga ao nacionalismo que the esteve na origem, não deixando de levantar muitas dúvidas, por invocar conceitos bem datados que, desde logo, remetem para um imaginário bem definido. $\mathrm{O}$ que, no quadro dos outros membros da Comunidade dos Países de Língua Portuguesa (CPLP), não se afigura, pelos vistos, problemático, já que o atual presidente venceu, já em 2021, o prémio José Aparecido da Oliveira, escolhido por consenso entre os membros do júri.

$\mathrm{Na}$ tomada de posse para o seu seguindo mandato, em 9 de março de 2021 (depois de ganhar as eleições por maioria absoluta, logo à primeira volta, tal como sucedeu no primeiro mandato), Marcelo Rebelo de Sousa, parece ter querido seguir o mesmo caminho que traçou até aqui, continuando a enredar o seu discurso nessa teia luso tropical, salientando pretender uma melhor democracia, que não seja sacrificada "ao mito do português puro, da casta indominada, dos antigos e novos privilegiados" (Presidência da República, 2021, s.p.). Restando esclarecer qual o entendimento atribuído a "português puro"...

\section{Referências bibliográficas}

Almeida, S. J. (2020, Novembro, 7). Marcelo Rebelo de Sousa inaugurou o presidencialismo simbólico. Público, p. 18.

Arendt, H. (1958/1998). The Human Condition. Chicago: University of Chicago Press.

Aronczyk, M. (2013). Branding the nation: The global business of national identity. New York: Oxford University Press.

Bardin, L. (2018). Análise de Conteúdo. Lisboa: Edições 70.

Botelho, L. (2016, Junho,11). A elite portuguesa em Paris e o Presidente Hollande aplaudiram as gardiennes, Público, pp. 4-5.

Botelho, L. (2020, Junho, 11). É a altura de "acordar" para a mudança necessária, diz Marcelo. Público, pp. 10-11.

Botelho, L. (2020, Dezembro, 8). O Marcelo de sempre recandidata-se porque "cada português conta". Público, pp. 2-4.

Bourdieu, P. (1982). Ce que parler veut dire: l'économie des échanges linguistiques. Paris: Fayard.

Cardina, M. (2014). O colonialismo nunca existiu? Buala, 20 de novembro de 2014. Retirado de http://tinyurl.com/ qfwwbzw

Castelo, C. (2011). O Modo português de estar no mundo. Porto: Edições Afrontamento.

Castelo, C. (2013, 5 de março). O luso-tropicalismo e o coIonialismo português tardio. Buala. Recuperado de: https:// tinyurl.com/p2kyd9r

Coelho, A. L. (2016, Março, 13). A pele de Cavaco e os milagres de Marcelo. Público, p. 45.

Comunidades Lusófonas (2017, 14 de Abril). "Portugueses são admirados em todo o mundo, não têm inimigos". Recuperado de: https://tinyurl.com/cjc5rzhd

Expresso online (2018, 11 de Junho). Está dito. Recuperado de: https://tinyurl.com/48ftj44s

Fiorin, J. L. (1998). Linguagem e Ideologia. São Paulo: Ática.

Foucault, M. (1970/1999). A Ordem do Discurso. Aula Inaugural no Collège de France, Pronunciada em 2 de Dezembro de 1970. São Paulo: Edições Loyola.

Foucault, M. (1975/2010). Microfísica do Poder. Rio de Janeiro: Graal. 
Franco, J. E. (2000). O Mito de Portugal. A Primeira História de Portugal e a sua Função Política. Lisboa: Roma Editora.

Freyre, G. (1953). Um brasileiro em terras portuguesas. Lisboa: Livros do Brasil.

Freyre, G. (1961). O Luso e o Trópico: Sugestões em torno dos métodos portugueses de integração de povos autóctones e de culturas diferentes da europeia num complexo novo de civilização: o luso-tropical. Lisboa: Comissão Executiva das Comemorações do V Centenário da Morte do Infante D. Henrique.

Gil, J. (2018, Janeiro, 7). "Reinventar Portugal" - Sobre um discurso quase messiânico (sem Messias). Público, P2, p. 6.

Gomes, M. (2017, Junho, 11). Presidente pede um país livre do "atraso, da dívida e da sujeição". Público, pp. 8-9.

Gomes, M. \& Crisóstomo (2016, Março, 9). As notas ao discurso de Marcelo. Público, p. 6.

Gramsci, A. (1978). Concepção Dialética da História. Rio de Janeiro: Civilização Brasileira.

Lopes, M. J. (2016, Junho, 11). Elogio de um povo melhor do que as suas elites. Público, p. 6.

Lourenço, E. (1994). Nós e a Europa ou As Duas Razões. Lisboa: Imprensa Nacional-Casa da Moeda.

Lusa e Borges, L. (2020, 15 de Junho). Marcelo: é "verdadeiramente imbecil" vandalização de estátua do padre António Vieira. Público. Recuperado de: https://tinyurl.com/ yjhc3y93

Maffesoli, M. (1992/2005). A Transfiguração do Político. A Tribalização do Mundo. Porto Alegre: Editora Sulina.

Marinheiro, C. (2008, 23 de Janeiro). O "viver habitualmente" de Salazar. Portal Ciberdúvidas da Língua Portuguesa. Recuperado de: https://tinyurl.com/t8tedvhm

Martins, S. M. (2019, 29 de Janeiro). Marcelo condecorou o cónego João Seabra, um apaixonado pela educação. Rádio Renascença. Recuperado de: https://tinyurl.com/u4jdny5w

Marx, K. \& Engels, F. (1846/2001). A Ideologia Alemã. São Paulo: Martins Fontes.

Lopes, M. (2018, 11 de Junho). "Podia ser num 10 de Junho, mas não foi". O tweet polémico de Catarina. Notícias ao Minuto. Recuperado de: https://tinyurl.com/dajxmtff

Observador (2019, 22 de Março). Marcelo diz que portugueses são "os melhores dos melhores do mundo". Recuperado de: https://tinyurl.com/m49p3hck

Pardal, L. \& Lopes, E. S. (2011). Métodos e técnicas de investigação social. Maia: Areal Editores.
Pinto, J. (2019, 10 de Março). Marcelo e os banhos de multidão: a história revisitada. Observador. Recuperado de: https://tinyurl.com/4pszsrjs

Presidência da República (2016, 9 de Março). Discurso de Tomada de Posse do Presidente da República. Recuperado de: https://tinyurl.com/8ccbvzs4

Presidência da República (2017, 10 de Janeiro). Homenagem ao Presidente Mário Soares. Mosteiro dos Jerónimos. Recuperado de: http://tinyurl.com/k4clh6v

Presidência da República, (2017, 25 de Abril). Sessão Solene Comemorativa do 43.․ Aniversário do 25 de Abril (Assembleia da República). Recuperado em 22 março de 2021, de https://tinyurl.com/2uhvhkbf

Presidência da República (2017, 29 de Novembro). Presidente da República felicita o escritor e poeta Manuel Alegre pelo seu doutoramento "honoris causa" pela Universidade de Pádua. Recuperado de: https://tinyurl.com/yrjbca6y

Presidência da República (2018, 10 de Junho). Festival WaterFire e encontro com a Comunidade Portuguesa de Rhode Island. Recuperado de: https://tinyurl.com/5nh25c2u

Presidência da República (2021, 9 de Março). Discurso na Cerimónia de Tomada de Posse na Assembleia da República. Recuperado de: https://tinyurl.com/57cwxzsp

Quivy, R. \& Camepnhoudt, L. V. (2008). Manual de investigação em Ciências Sociais. Lisboa: Gradiva.

Rádio Renascença (2016, 29 de Março). Portugal, Março de 2016, segundo Marcelo: menos "crispação", mais "estabilidade". Recuperado de: https://tinyurl.com/pfw2vark

Rádio Renascença (2017, 4 de Março). Marcelo homenageou memória das vítimas de Entre-os-Rios. Recuperado de: https://tinyurl.com/29h9xshc

Ramos, R. (2018, 12 de Junho). 10 de junho_Um dia contra Portugal?. Observador. Recuperado de: https://tinyurl. com/3mb5uprx

República Portuguesa (1945). Carta Orgânica do Império Colonial Português. Nova publicação nos termos das portarias $n$-8:699 e 8:730, de 5 de Maio e 3 de Junho de 1937, 2ª edição oficial. Lisboa: Imprensa Nacional de Lisboa.

Ribeiro, N. (2019, Junho, 11). Presidente fala no 10 de Junho de exigência ética na vida pública. Público, pp. 8-11.

Risse, T. (2000). Let's Argue! Communicative Action in International Relations. International Organization, 1, 1-39.

Rodrigues, S. (2018, Junho, 11). Marcelo adverte para "volúpia das rupturas", Costa desvaloriza. Público, p. 6. 
Rosas, F. (2001). O Salazarismo e o homem novo: ensaio sobre o estado novo e a questão do totalitarismo. Análise Social, XXXV (157), 1031-1054.

Sá, P. (2017, 11 de Junho). Em 5 minutos, Marcelo fez várias declarações de independência. Diário de Notícias. Recuperado de: https://tinyurl.com/59yzwzv8

Sousa, M. R. (2016, 30 de Maio). Portugal, uma Pátria feita contra a sorte. Jornal de Negócios. Recuperado de: https:// tinyurl.com/yp5p5h67

Sousa, J. P. (2020, 26 de Julho). Lusotropicalismo e o mito da Portugalidade. Observador. Recuperado de: https://tinyurl. com/4h842tyn
Sousa, V. (2017). Da 'portugalidade' à lusofonia. Famalicão: Húmus

Stoer, S. R. \& Cortesão, L. (1999). "Levantando a pedra" - da pedagogia inter/multicultural às políticas educativas numa época de transnacionalização. Porto: Afrontamento.

Valente, V. P. (2020, Janeiro, 18). Diário, 13 de janeiro. Público, p. 7

Waever, O. (2002). Identity, Communities and Foreign Policy: Discourse Analysis as Foreign Policy Theory. In Hansen, L, \& Waever, O. (Eds.), European Integration and National Identity. The Challenge of the Nordic States (pp. 20-49). Londres: Routledge. 